\title{
The association of HIV and easy access to narcotics in Pakistan; calling drug policy makers
}

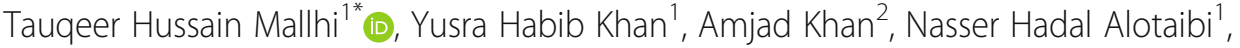 \\ Abdulaziz Ibrahim Alzarea ${ }^{1}$ and Furqan Khurshid Hashmi ${ }^{3}$
}

\begin{abstract}
HIV in Pakistan is concentrated to people who inject drugs (PWID) and easy accessibility of narcotics to this population cannot be disregarded as a risk factor of growing encumbrance of AIDS in the country. All the narcotics and other medications having high potential of abuse are stratified into Schedule G of Punjab Drug Rules 2017. According to these rules, drugs in Schedule $G$ shall be sold in pharmacy under the direct supervision of qualified pharmacist. However, Schedule $\mathrm{G}$ is not implemented in Punjab due to continuous resistance from pharmaceutical stakeholders including medical store owners (who are barred to sell drugs from schedule G). Since 1.6 million PWID reported misuse of prescription opioids for non-medical use, delayed implementation of schedule $G$ is attributing to the unabated sale of narcotics without prescription and for non-medical purposes, which is further contributing to the staggering number of PWID in the country. Implementing schedule G will not only curb the existing situation of HIV but will also mitigate the contribution of PWID towards the future events.
\end{abstract}

Keywords: HIV, Schedule G, Drug act, Drug policy, Narcotics abuse, PWID, Pakistan, Drug act

\section{Dear Editor,}

In 2019, an unprecedented number of HIV positive cases have been recorded in Pakistan (Fig. 1). Several health experts across the country reported the outbreak and underscored various contributing factors of this menace [1-4]. A recent rural epidemic of HIV in Sindh province of Pakistan is reported to be caused by poor disease awareness and literacy in rural community, use of contaminated syringe by a quack impersonating a doctor and limited coverage of national AIDS control program (NACP) [2]. Similar outbreak has been experienced in Punjab province, where prevalence of HIV hiked from 1.29 to $13.38 \%$ in Kot Imrana (a small village in Punjab) during a brief period of 6 months. Most important drivers of this outbreak were the unsafe use of syringes through quackery followed by poor coordination among healthcare

\footnotetext{
* Correspondence: tauqeer.hussain.mallhi@hotmaill.com

${ }^{1}$ Department of Clinical Pharmacy, College of Pharmacy, Jouf University,

Sakaka, Al-Jouf, Kingdom of Saudi Arabia

Full list of author information is available at the end of the article
}

departments [1]. Other factors linked to the current HIV situation in Pakistan are unsafe blood transfusion, reuse of needles, male circumcision with unhygienic blades, and ear and nose piercing with unsafe needle. The contribution of these factors to the HIV epidemics is alarming and we urge NACP, World Health Organization (WHO) and UNAIDS to address these momentous issues.

It is pertinent to mention that HIV epidemics in Pakistan are primarily concentrated to the people who inject drugs (PWID), accounting approximately $38 \%$ of currently registered patients $[1,5]$. Since PWID pose themselves to the imminent risks of contracting $\mathrm{HIV}^{6}$, we felt inclined to share that accessibility of injectables (i.e. narcotics) to this population should also be considered among causes of HIV and must be addressed by the Government of Pakistan in haste to quell the further disease spillover. In all previous reports, this factor is neglected by health professionals; thereby we took an opportunity to demonstrate the relationship of uncontrolled sale of narcotics/opioids and recent HIV outbreak in Pakistan. 


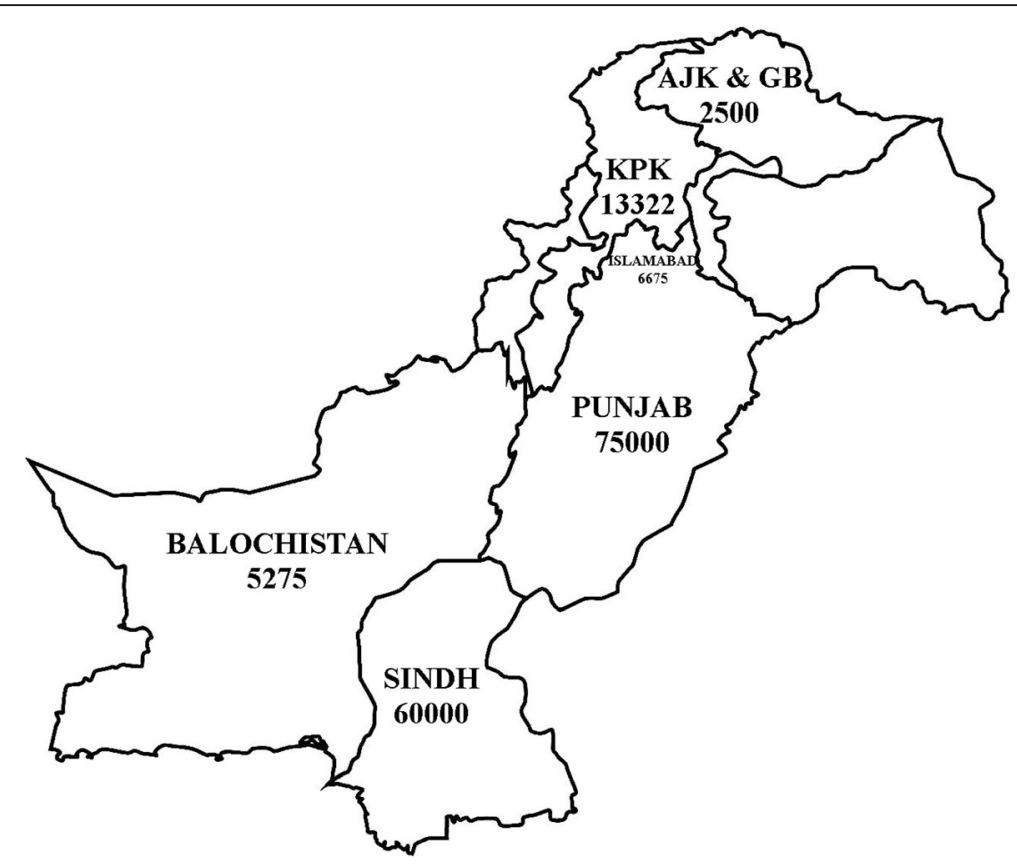

Fig. 1 Confirmed Cases of HIV in Pakistan (AJK \& GB: Azad Jammu and Kashmir \& Gilgit-Baltistan, KPK: Khyber Pakhtunkhwa), Source: Reference [16]

PWID are driving HIV epidemic in Pakistan since last decade and count substantial proportion of HIV patients currently registered and receiving antiretroviral therapy (ART) [1,5-7]. Due to its large share of the population; Punjab has the highest number of drug users with approximately 260,000 PWID. HIV prevalence among PWID has steadily increased from $10.8 \%$ in 2005 to $27.2 \%$ in 2011. Alarmingly, several cities in Pakistan reported $<40 \%$ prevalence of HIV among PWID, including Faisalabad (52.5\%), D.G. Khan (49.6\%), Gujrat (46.2\%), Karachi (42.2\%) and Sargodha (40.6\%). The latest round of Integrated Biologic and Behavioral Surveillance Survey (IBBS) indicated a weighted prevalence of PWID as $36.8 \%$ among ten cities of Punjab [8]. Based on a model by Reza et al., the total number of PWID infected with HIV may reach 68,000 by 2020 [9]. A report of UN office of Drugs and Crimes (UNODC) concludes that about 6.7 million drug users have easy access to opiates in Pakistan [10-12]. Of these, nearly 1.6 million people reported misuse of prescription opioids for non-medical use [11]. A recent estimate of NACP concluded that preferred drugs of choice for PWID in Pakistan are $\mathrm{AVIL}^{\circ}$ (injection containing antihistamine pheneramine maleate) and heroin. This report evaluated the pattern of drug use among PWID from 14 cities of Pakistan and found the use of several pharmaceutical products including Valium ${ }^{\circ}$ (Diazepam), Phenergan ${ }^{\circ}$ (Promethazine) and Restoril $^{\circ}$ (Temazepam) [8]. These findings underscore that substantial proportion of PWID has access to the prescription narcotics in the country. Despite these upsetting figures, delayed implementation of schedule G is further facilitating the access to these dangerous drugs, contributing to the staggering number of PWID in the country.

There are two types of drug sale outlets in Pakistan; Pharmacy (Category A: operated under the direct supervision of qualified pharmacist using license Form-9) and Medical Store (Category B: operated by non-pharmacist individuals under license Form-10). According to the Punjab Drug Rules 2007 under section 44 of Drugs Act 1976, around 145 lifesaving and vital medications are stratified into Schedule G. All narcotics and other medications having high potential of drug abuse are included in Schedule G (Additional file 1). These rules barred licensees of medical store (category B) from selling medications from schedule G [13]. However, schedule G was not implemented in the province and allowed grace period of 10 years following the severe resistance and series of protests by licensees or owners of medical stores. Recently in 2017, Government of Punjab amended the rules by implementing the schedule $G$ and restricted the sale of narcotics by pharmacies under the supervision of qualified pharmacists. But the conditions did not differ much from the last incident and these amendments caused worst shutter down strike from chemists, medical store retailers and manufacturers across the province. Subsequently, these amendments have been withdrawn and further grace period of six years (till 2023) was agreed for the implementation of schedule G [14]. Since majority of the salespersons 
working on medical stores did not even attend college and lack formal education on drug use, continuous relaxation of schedule $G$ is attributing to the uncontrolled sale of opiates/narcotics without any prescription and for non-medical purposes.

On the other hand, most of the pharmacies in Pakistan are running unauthorized on rented drug sale license in the absence of qualified pharmacists. These pharmacies are managed by a diverse group of dispensers having no authority to sell medications. Though Pharmacy Council and Court of Law has directed that renting pharmacy registration is a crime but practice is rampant in connivance with officials of health departments [15]. This malpractice is further promoting the unabated sale, availability and accessibility of opiates/narcotics and other controlled substances for non-medical purposes.

We believe that growing encumbrance of AIDS in the country is also associated with uncontrolled sale and access of injections to PWID. These factors tend to surge the proportion of PWID not only in Punjab but also in other provinces of Pakistan, thereby facilitating the risks of HIV in the country. Since considerable contribution of PWID in the existing situation of HIV and poor coverage of AIDS control program to this population cannot be disregarded, there is dire need of legislative and control strategies to prevent the unabated sale of prescription drugs to PWID. Implementing schedule G, ensuring physical appearance of pharmacists during drug sale process, fostering the prescription sale of narcotics and crackdown against illicit sale of drugs to PWID will not only assist NACP to curb the existing situation but will also mitigate the contribution of PWID towards the future events. It is important to mention that schedule $G$ will only preclude the irrational sale of drugs to PWID while accessibility of street drugs from illicit markets will remain unaffected. Ministry of Health can play a crucial role by constructing a national body consisting of representatives from NACP and Drug Regulatory Authority of Pakistan (DRAP) to mitigate the hazards of PWID involvements in HIV epidemics. We strongly believe that collaborative and coordinated maneuvers between DRAP, NACP and provincial primary/secondary healthcare departments (P\&SHC) would have synergetic impact and could go a long way in combating the AIDS in Pakistan. Moreover, it is of utmost importance to explore the sources of drug supply to PWID in Pakistan through well-structured studies.

\section{Supplementary information}

Supplementary information accompanies this paper at https://doi.org/10. 1186/s40545-019-0199-5.

Additional file 1. Schedule G under Punjab Drug Rules 200.
Authors' contributions

THM and YHK conceived the concept and drafted the manuscript. FKH and AK collected relevant literature and gave final approval of draft. All authors read and approved the final manuscript.

\section{Authors' information}

All authors hold PhD degree in Clinical Pharmacy and Pharmacy Practice. Dr. THM and YHK serve as assistant professor in Department of Clinical

Pharmacy at GC Jouf University KSA. Dr. NHA is Dean at College of Pharmacy Dr. AIA heads Department of Clinical Pharmacy. Dr. Furqan Khurshid Hashmi serves as In-charge at Section of Pharmacy Practice, University of the Punjab, Pakistan. Dr. Yusra Habib Khan and Dr. Amjad Hayat Khan are stream leaders in Clinical Pharmacy in their respective institutes and possess broad experience of pharmacy practice research, particularly utilization of medication in kidney patients. All authors are active researchers and contribute substantially in the field of Pharmacy Practice.

\section{Funding}

There is no funding for this manuscript.

Availability of data and materials

Not Applicable.

Ethics approval and consent to participate

Not Applicable.

\section{Consent for publication}

All authors are agreed to submit the manuscript in JoPPP.

\section{Competing interests}

The authors declare that they have no competing interests.

\section{Author details}

${ }^{1}$ Department of Clinical Pharmacy, College of Pharmacy, Jouf University, Sakaka, Al-Jouf, Kingdom of Saudi Arabia. 'Department of Pharmacy,

Quaid-i-Azam University, Islamabad 45320, Pakistan. ${ }^{3}$ University College of Pharmacy, University of the Punjab, Allama lqbal Campus, Lahore 54000, Pakistan.

Received: 29 August 2019 Accepted: 21 November 2019

Published online: 18 December 2019

\section{References}

1. Ahmed A, Hashmi FK, Khan GM. HIV outbreaks in Pakistan. Lancet HIV. 2019; 6(7):PE418.

2. Arif F. HIV crisis in Sindh, Pakistan: the tip of the iceberg. Lancet Infect Dis. 2019;19(7):695-6.

3. Green A. HIV epidemic in children in Pakistan raises concern. Lancet. 2019; 393(10188):2288.

4. Organization WH. HIV cases - Pakistan, disease outbreak news 2019 [cited 2019 October 9]. Available from: https://www.who.int/csr/don/03-july-2019hiv-cases-pakistan/en/.

5. Programme NAC. Current statistics: NACP; 2019. Available from: https:// www.nacp.gov.pk/\#

6. Samo RN, Altaf A, Agha A, Pasha O, Rozi S, Memon A, et al. High HIV incidence among persons who inject drugs in Pakistan: greater risk with needle sharing and injecting frequently among the homeless. PLoS One. 2013:8(12):e81715

7. Bergenstrom A, Achakzai B, Furqan S, ul Haq M, Khan R, Saba M. Drugrelated HIV epidemic in Pakistan: a review of current situation and response and the way forward beyond 2015. Harm Reduct J. 2015;12(1):43.

8. Program NAC. Integrated Biological \& Behavioral Surveillance in Pakistan 2016-17, second generation HIV surveillance in Pakistan round 5; 2017.

9. Reza T, Melesse DY, Shafer LA, Salim M, Altaf A, Sonia A, et al. Patterns and trends in Pakistan's heterogeneous HIV epidemic. Sex Transm Infect. 2013; 89(Suppl 2):ii4-ii10.

10. Ahmed D. Heroin and extremism in Pakistan 2015 [updated AUGUST 17, 2015; cited 2019 August 14]. Available from: https://foreignpolicy.com/2015/ 08/17/heroin-and-jihad-in-pakistan/.

11. Crime UNOoDa. UNODC Pakistan; country profile: UNODC; [cited 2019 October 10]. Available from: https://www.unodc.org/pakistan/en/country-profile.html. 
12. Crime UNOoDa. Sucess stories from UNDOC. 2013.

13. Javeed A, Mahmood KT. Community pharmacy practice in Pakistan: from past to present-a review. J Pharm Sci Res. 2012;4(2):1703.

14. Malik A. Deadlock over drugs act persists aschemists hold protest. News Int 2018. Weblink: https://www.thenews.com.pk/print/310789-deadlock-overdrugs-act-persists-aschemists-hold-protest.

15. The Newspaper Staff Report. Court orders action against pharmacies on rented credentials. Dawn. 2016. Weblink: https://www.dawn.com/news/1243 022.

16. NewsLab TET. In Larkana, a scourge of African proportions 2019 [cited 2019 October 10, 2019]. Available from: https://newslab.tribune.com.pk/the-silentspread-of-hiv/.

\section{Publisher's Note}

Springer Nature remains neutral with regard to jurisdictional claims in published maps and institutional affiliations.

Ready to submit your research? Choose BMC and benefit from:

- fast, convenient online submission

- thorough peer review by experienced researchers in your field

- rapid publication on acceptance

- support for research data, including large and complex data types

- gold Open Access which fosters wider collaboration and increased citations

- maximum visibility for your research: over $100 \mathrm{M}$ website views per year

At BMC, research is always in progress.

Learn more biomedcentral.com/submissions 